WIENER SLAVISTISCHES JAHRBUCH, Band 56/2010, 121-136

(C) 2010 by Österreichische Akademie der Wissenschaften, Wien

Eva Maria OSSA DNíK

\title{
Die Neubildung von Wörtern des kroatischen Zivilisations- wortschatzes des frühen 19. Jahrhunderts am Beispiel des Wortschatzes für Versicherungswesen (1847)
}

1.1. Die von Herder und der deutschen Romantik inspirierte Nationale Wiedergeburt der Slawen, die zuerst bei den Tschechen Auswirkungen auch auf die Sprache hatte, fand im Kroatischen ihren Ausdruck in der Illyrischen Bewegung (,Ilirski

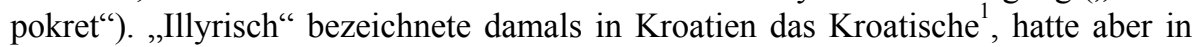
der Bezeichnung der Illyrischen Bewegung bereits eine politische Konnotation.

1.2.1. Diese Bewegung wollte eine gemeinsame Sprache der Südslawen bilden und das Kroatische von Fremdeinflüssen befreien; in ihrer Auswirkung auf die Neubildung von Wörtern des kroatischen Zivilisationswortschatzes in der ersten Hälfte des 19. Jahrhunderts ist sie bisher in relativ geringem Ausmaß bearbeitet worden ${ }^{2}$, da sie vor allem eine politische Bewegung war (vgl. Moguš 1995: 150).

1.2.2. Die „Illyrische Bewegung“ hatte puristische Auswirkungen auf den kroatischen Wortschatz. Es gab auch noch andere linguistische Prozesse, die durch sie in Gang gesetzt wurden, wie z. B. eine Reform der Orthographie oder die Festlegung der Dialektbasis der kroatischen Standardsprache; mit diesen Vorgängen befassen wir uns hier nicht.

1.2.3. Mit der „Illyrischen Bewegung“, die sich in der Folge zur kroatischen nationalen Wiedergeburt entwickelte (vgl. Jonke 1975: 67), begann das kroatische Zeitungswesen (vgl. Katičić 2004: 19-27): Ljudevit Gaj, der prominenteste Vertreter dieser Bewegung (vgl. z. B. Šicel 1985: 18), gab seit 1835 die Tageszeitung „Novi-

${ }^{1}$ Zu ilirski vgl. Thomas 1988: 15-16 und Behschnitt 1980: 133-160; in den Grazer Universitätsmatrikeln wird 1587 erstmals illyricus für 'kroatisch' verwendet (Fancev 1936: 133) - hier sieht man, dass dieses Wort auch ohne politische Implikationen verwendet werden konnte.

2 Vgl. Thomas 1988 mit einer Übersicht über die bisherige Literatur (S. 26-34). 
ne dalmat. horvatsko-slavonske ${ }^{\text {c }^{3}}$, kurz „Narodne novine“ 'Nationalzeitung', heraus, die wie die ebenfalls von ihm herausgegebene literarische Zeitschrift „Danica ilirska“ eine Plattform zur Verbreitung der Ideen des Illyrismus und der Sprachreform war (vgl. Despalatović 1975: 79). Sie hieß ursprünglich nicht 'Dalmatinisch-kroatisch-slawonische Zeitung', sondern 'Kroatische Zeitung' (Novine horvatzke), seit 1836 'Illyrische Nationalzeitung' (Ilirske narodne novine) - Lj. Gaj führte damit in den Diskurs der Nationalen Bewegung ilirski ein (s. Početci 2006: 27). Metternich verbot 1843 den Gebrauch von ilirski aus politischen Gründen, denn die Entstehung einer nicht-deutschen nationalen Bewegung innerhalb der Habsburger-Monarchie war nicht erwünscht (Bauer 1942: 34, Thomas 1988: 17, Suppan 1996: 114-122, Garde 2004: 189) ${ }^{4}$, , sodass der Titel dieser Zeitung geändert werden musste. Mit diesem Verbot wurde in Zagreb und in ganz Banal-Kroatien eine schärfere Zensur eingeführt (vgl. Bauer 1942: 34).

1.3. Während die politische Seite dieser Bewegung in der Literatur reich dokumentiert ist, sind ihre linguistischen Auswirkungen bis jetzt spärlich bearbeitet worden, vgl. dazu z. B. Auty 1972: 48, dessen diesbezügliche Feststellung trotz der Arbeit von Thomas 1988 nach wie vor aktuell ist. Auty 1972: 51 hebt außerdem hervor, dass $\mathrm{Lj}$. Gaj in der Bereicherung der kroatischen Lexik eine größere Rolle spielt, als das bis dahin erkannt worden ist.

2.0.1. In diesem Aufsatz wollen wir am Beispiel der Wörter für das Versicherungswesen einen linguistischen Teilaspekt der Wirkungskraft der „Illyrischen Bewegung" darstellen. Das Material für diese Arbeit stammt aus dem kroatischen Teil des Forschungsprojekts „'Gesellschaft' und 'Wirtschaft': Bosnisch, Kroatisch, Serbisch", das von 2003 bis 2007 in der Balkan-Kommission der Österreichischen Akademie der Wissenschaften unter der Leitung von Herrn Prof. Dr. G. Neweklowsky bearbeitet wurde .

2.0.2.1. Hier beschreiben wir in einem synchronen Schnitt den Wortschatz des zur damaligen Zeit zum Großteil neuen Versicherungswesens; dieser Beschreibung wird der heute gebräuchliche Wortschatz dieses Sachgebiets gegenübergestellt. Die Neubildung von Teilen des Wortschatzes, die durch die technisch-wirtschaftliche Entwicklung notwendig wurde, steht unter dem Einfluss der Illyrischen Bewegung, kann aber nicht durch deren Einwirkung allein erklärt werden.

2.0.2.2. Da die Illyrische Bewegung von der urbanen Bevölkerung getragen wurde (vgl. Thomas 1988: 70), stellt der Wortschatz des Versicherungswesens einen repräsentativen Teil der Wörter dar, die von den sprachlichen Wirkungen der Illyri-

${ }^{3}$ Wir benützen - außer in zeitgenössischen Zitaten, die als Beispiel verwendet werden - die moderne kroatische Orthographie, da die Rechtschreibung des Kroatischen nicht Thema dieses Aufsatzes ist und auf die behandelte Fragestellung weiter keinen Einfluss hat.

${ }^{4}$ Der Gebrauch von ilirski als literarischem Terminus im Text wurde erst 1844 erlaubt, vgl. Thomas 1988: 17.

5 Die Idee zu diesem Projekt stammt von Herrn Prof. Dr. R. Katičić. 
schen Bewegung erfasst wurden: Die Volkssprache des bäuerlichen Milieus in der ersten Hälfte des 19. Jahrhunderts reichte für die Benennung von Neuem nicht aus (vgl. Jonke 1965: 20).

2.0.3. 1847 wurden in der Nummer 28 der Zeitung „Novine dalmat.-horvatskoslavonske“ vom 7. April auf zwei Seiten im Format A3 die Angebote der „Azienda Assicuratrice" in Triest dargestellt, als erstes die Bedingungen für eine Wasserschadenversicherung, die damals erstmals auf den Markt kam. Wie man bei der Sichtung der historischen Belege zum Wortschatz betreffend das Versicherungswesen feststellen kann, wurde dieser Wortschatz im behandelten Zeitungsartikel erstmals vorgestellt. Auf welche Weise er gebildet wurde, wollen wir in diesem Aufsatz darstellen.

2.1. Das Verbum osigura(va)ti ${ }^{6}$ war schon früher belegt, und zwar in der Bedeutung 'sichern, sicherstellen'. Diese Bedeutung ist auch in „Narodne novine“ belegt und heute auch noch möglich (Katičić) ${ }^{7}$. In der Bedeutung 'versichern' ist es laut dem im beschriebenen Projekt erarbeiteten Material 1847 erstmals belegt, und zwar in Lj. Gajs Zeitung „Narodne novine“. Laut dem „Rječnik hrvatskoga ili srpskoga jezika", das in der Südslawischen Akademie der Wissenschaften in den Jahren 1854-1975 erschienen ist (im Folgenden als „ARj.“ abgekürzt), stammt der Erstbeleg für osigurati aus dem Jahr 1853 (JPT), der für osiguravati aus dem Jahr 1860 (Šulek). Das beschriebene Forschungsprojekt kann in diesen und in weiteren Fällen ältere Erstbelege bieten.

2.2.1. Das vom perfektiven Verbalaspekt abgeleitete Substantiv osiguranje bedeutete vor 1847 'Absicherung, Sicherstellung' (vgl. ARj. s. v.); diese Bedeutung ist bis heute kontextabhängig möglich (Katičić). Die Semantik 'Versicherung' findet sich laut dem uns zugänglichen Material schon 1847 in „Narodne novine“, der Erstbeleg für diese Bedeutung stammt also nicht wie im ARj. angegeben aus JPT 1853. Heute bezeichnet osiguranje sowohl das Versicherungsunternehmen als auch die von ihm angebotene Dienstleistung und ist also genauso zweideutig wie das deutsche Versicherung.

2.2.2. Rammelmeyers Feststellung (1. c.), osiguranje 'Versicherung' sei etwa seit der Mitte des 19. Jahrhunderts belegt, können wir in diesem Aufsatz bestätigen und präzisieren, da Neologismen zuerst in Zeitungen und Zeitschriften aufscheinen.

2.3.1. Das vom imperfektiven Verbalaspekt abgeleitete Substantiv osiguravanje bezeichnete die Dienstleistung einer Versicherung, seine heutige Bedeutung ist 'das Versichern' (Katičić). Das ARj. gibt s. v. osiguravanje als ältesten Beleg für dieses

${ }_{7}^{6}$ Die zugehörigen Belege und Textbeispiele finden sich in Teil 7.

7 So gekennzeichnete Angaben über das heutige Kroatische stammen von Herrn Prof. Dr. Radoslav Katičić, der auch Vorsitzender des Rates für die Norm der kroatischen Standardsprache (Vijeće za normu hrvatskog standardnog jezika) des Ministeriums für Wissenschaft, Bildung und Sport der Republik Kroatien ist. Wir bedanken uns bei ihm für Konsultation. 
Wort Šulek 1860 an, es ist als osěguravanje aber bereits im Wörterbuch von Mažuranić-Užarević ${ }^{8}$, das 1842 im Verlag der „,kaiserlichen privilegirten ilirischen National-Buchdruckerei von Dr. Ljudevit Gaj“ in Zagreb erschienen ist, belegt, auch in „Narodne novine“ 1847.

2.3.2. 'Versicherung' osiguravanje bzw. osiguranje und 'versichern' osiguravati bzw. osigurati stellen nach Rammelmeyer 1975: 241 Lehnübersetzungen aus dem Deutschen dar; diese Annahme ist unserer Meinung nach ungenau, da das deutsche Präfix ver- nicht mit $o$ - übersetzt wird. Es handelt sich bei o-sigur-a-vanje 'Versicherung' (dem Produkt, das eine Versicherungsgesellschaft anbietet) vielmehr um eine Lehnprägung ${ }^{9}$ nach dem italienischen as-sicur-a-zione; diese Annahme wird dadurch gestützt, dass osiguravanje in der Bedeutung 'Versicherung' zum ersten Mal in einem Zeitungsartikel belegt ist, der die Angebote einer italienischen Versicherung - nämlich der Azienda Assicuratrice - anpreist. Die Situation wird allerdings dadurch kompliziert, dass um 1847 die Versicherung im Deutschen, das zu dieser Zeit einen starken Einfluss auf das Kroatische ausübte, Assekuranz hieß. Kroat. sigur- wurde aus dem (venezianischen) Italienischen entlehnt ${ }^{10}$; das war aber viel früher der Fall, als es Versicherungen in Kroatien gab: Der Erstbeleg für sigur stammt nach ARj. aus der Zeit um 1400 (Žića otaca): Budeš slobodan i sigur od svitnih pečal.

2.4. Das Versicherungsunternehmen wurde als Übersetzung des deutschen Versicherungsgesellschaft osigurajuće družtvo oder družtvo za osiguranje genannt, auch dtsch. Versicherungsanstalt diente als Übersetzungsvorlage, was osigurajuć $i$ zavod in „Narodne novine“ ergab; heute osiguravajuće društvo. Die „Osiguranje Zagreb" bezeichnet sich auf ihrer Website selbst als osigurateljno društvo, also eigentlich 'Versicherergesellschaft'; dieser Ausdruck ist nach R. Katičić äußerst unüblich.

2.5. Weitere Lehnübersetzungen aus dem Deutschen sind 'Versicherer' osiguratelj, 'Versicherter, Versicherungsnehmer' osigurani, 'Versicherungsantrag' prošnja za osiguranje, 'Versicherungsbedingung' uvět osiguravanja, 'Versicherungsbranche' struka osiguravanja, 'Versicherungskapital' osiguravajuća glavnica, 'Versicherungssumme' osigurana suma (heute svota osiguranja) und 'Versicherungswert' osigurana vrëdnost (heute vrijednost osiguranog objekta). Ein Versicherungsnehmer wurde als udionik osiguranja, also als 'Teilnehmer einer Versicherung', bezeichnet; statt dieses Ausdrucks, der heute unter keinen Umständen mehr verwendet werden kann (Katičić), wird heute osiguranik (das Femininum dazu lautet osiguranica, das zugehörige Adjektiv osiguranički) gebraucht.

${ }^{8}$ Dieses Wörterbuch war das erste, das in der Zeit der Illyrischen Bewegung erschien (vgl. Jonke 1958: 86). Es wurde in ARj. nicht ins exzerpierte Material aufgenommen.

9 Vgl. Turk 1997: 87.

10 Skok 1971-1973 s. v. sikür-. 
2.6. Folgende Wörter waren bereits vorhanden und wurden nun in diesem neuen Kontext verwendet: agent '(Versicherungs-)Agent', izplaćivati/izplatiti 'auszahlen', izplaćivanje 'Auszahlung', na(do)knada 'Entschädigung', izvidjeti 'ermitteln', glavnica 'Kapital', namirivati 'vergüten', šteta bzw. kvar 'Schaden', (pro)cěniti 'schätzen (in finanzieller Hinsicht)', statute/statute 'Statuten' und tarifa 'Tarif'.

2.7. Auch das Wort für 'Prämie' war bereits vorhanden: Es war aus dem Deutschen entlehnt worden ${ }^{11}$ und bezeichnete eine finanzielle Belohnung; diese Bedeutung ist auch heute üblich und steht in den Wörterbüchern des modernen Kroatischen an erster Stelle. Für den Gebrauch dieses Wortes im Zusammenhang mit 'Versicherung' als Bezeichnung eines Geldbetrags, der erlegt werden muss, ist premia, das in älteren Wörterbüchern und auch in etymologischen Werken nicht vorkommt, in „Narodne novine“ zum ersten Mal belegt.

2.8. Der Ausdruck für '(un)bewegliche Habe' bzw. '(un)bewegliches Gut' war erst in Entstehung begriffen und daher nicht einheitlich: Die bewegliche Habe wurde im Zusammenhang mit der Versicherung als gibivo imanje bezeichnet, zwei Seiten weiter wurde sie gibivo dobro 'bewegliches Gut' genannt - beide Wortbildungen sind Lehnübersetzungen aus dem Deutschen. Heute heißt 'bewegliche/s Habe/Gut' pokretnina. Die Immobilie wird im Kontext mit der Versicherung als negibivo dobro bezeichnet, 3 Seiten früher in einem anderen Kontext als negibivi imetak-auch diese Wortbildungen sind Lehnübersetzungen aus dem Deutschen; heute heißt die Immobilie im Kroatischen nekretnina.

3.0. Fremdwörter wurden oft durch ein mit kroatischen Mitteln gebildetes Wort ersetzt; im hier besprochenen Material kommt eine puristisch motivierte Neubildung in folgenden Fällen vor:

3.1. Agent wurde durch (auch heute noch in diesem Kontext verwendetes) zastupnik ersetzt, agencia hingegen durch opravničtvo; opravnik ist in N1847 auch belegt, jedoch in diplomatischer Hinsicht und mit dem Synonym agent in Klammern.

3.2. Der Ersatz von fond durch glavnica, das bereits 'Kapital' bedeutete, ist nicht gelungen: Fond 'Fonds' ist 1847 in Nr. 11 von „Narodne novine“ und in „Danica ilirska" belegt, beide Male ohne erklärendes Synonym in Klammern; čuvarna glavnica wurde in Nr. 28 von „Narodne novine“ mit Reservefond in Klammern erklärt hier ist 'Fonds', für das es schon das Wort fond gegeben hat, versuchsweise durch glavnica übersetzt worden.

3.3. Transport sollte durch prevoz ersetzt werden; heute sind sowohl transport als auch prijevoz erhalten.

4.1. Wörter zur Bezeichnung mancher Denotate mussten überhaupt neu gebildet werden, wobei es zu teils ungeschlachten Umschreibungen kam, die meist nicht erhalten blieben: Diese Umschreibungen waren nicht nur durch die Neuheit der be-

11 Anić - Goldstein 2000 s. v. prèmija. 
zeichneten Denotate bedingt, sondern auch durch die Struktur des Kroatischen, das im Gegensatz zum Deutschen keine Komposita bilden kann, z. B.: 'Bagatellschaden' šteta na jednom i istom predmetu, koje samo 5\% ili manje iznose (heute neznatna šteta), 'Feuerversicherung' osiguravanje proti kvarom od požara (heute osiguranje od opasnosti požara [Os. Z.]), 'Lebensversicherung' osiguranje života (heute životno osiguranje [Os. Z.]) und 'Wasserversicherung' (osiguravanje proti vodi).

4.2. Die Bildung des Wortes für 'Transportversicherung' (osiguravanje proti putnim pogibeljim pri prenosih od robe) wurde dadurch kompliziert, dass auch 'Transport' (hier prenos) zu den Wörtern gehörte, die infolge der puristischen Bestrebungen der Illyrischen Bewegung mit kroatischen Sprachmitteln wiedergegeben werden mussten (s. 3.3); die komplizierte Umschreibung von 'Transportversicherung' blieb jedoch nicht erhalten - dieses Denotat wird heute mit transportno osiguranje (Os. Z.) bezeichnet.

4.3. Die Wasserversicherung wurde als Lehnübersetzung des Deutschen (von einer Versicherung gegen den Schaden, den Wasser anrichten kann, ist nicht die Rede) osiguranje proti vodi genannt. Die Versicherung gegen Naturgewalten - osiguravanje proti svim elementarnim kvarom - wird bis heute sowohl auf Kroatisch als auch auf Deutsch umschrieben. 'Wasserschaden' wurde mit vodena šteta, das sich nicht durchgesetzt hat, und mit šteta od vode, das bis heute erhalten ist, wiedergegeben: Beide Ausdrücke kommen in der Darstellung der Leistungen der Azienda Assicuratrice nebeneinander vor - hier musste sich erst eine Norm etablieren, so dass eine gewisse Zeit lang zwei Ausdrücke nebeneinander standen; in einem solchen Fall konnte sich ein Ausdruck durchsetzen, der andere blieb nicht erhalten.

4.4. Solche Neubildungen, die sich nicht durchsetzen konnten und also gewissermaßen nur kurze Zeit am Leben waren, wurden von Thomas 1988: 111 nicht ganz zutreffend als ,still-births“ ('Totgeburten') bezeichnet.

4.5.1. Wir verstehen „Neologismus“ so, wie dieser Terminus bei Metzler 1993 definiert wird: „eine durch Neubildung oder Entlehnung neu entstandene lexikalische Einheit, die (noch) nicht Eingang in das Lexikon der betr. Sprache gefunden hat".

4.5.2. Thomas 1988: 72, 93-94 und 102 wundert sich über die geringe Anzahl von Neologismen im Wortschatz, der durch die Illyrische Bewegung beeinflusst worden ist. Wenn man sich mit dieser Materie beschäftigt, sieht man, dass es in diesem Wortschatz eine große Zahl von Neologismen gibt.

4.5.3. Ein untrügliches Zeichen dafür, dass es sich bei einem Wort tatsächlich um eine Neubildung handelt, die wahrscheinlich noch nicht allen bekannt war $^{12}$, ist,

${ }^{12}$ Vgl. Bußmann 2002 s. v. Neologismus: Neologismen „,werden ... von den Sprechern noch als neu empfunden und sind stilistisch entsprechend markiert. N. entstehen zur Benennung neuer Gegenstände und Konzepte, etwa in Technik, Wissenschaft oder Politik ..." und Katičić 2007: 306-307: „Der Umstand, dass in kroatischen Zeitungen dieser Zeit Wörter in Klammern übersetzt wurden, zeigt, dass man damals nicht unbedingt damit 
dass es in Klammern durch ein deutsches - die Leser dieser Zeitung waren so gebildet, dass sie Deutsch problemlos verstanden (vgl. Thomas 1988: 92) - Synonym erklärt wird, wofür es in dem in diesem Aufsatz behandelten Material zwei Beispiele gibt, und zwar družtvo za osiguranje života (Lebensversicherungsanstalt) und čuvarna glavnica (Reservefond) ${ }^{13}$.

5.1. In Nummer 29 von „Narodne novine“ vom 10. April kündigte der Versicherungsvertreter J. Spierer in einer Annonce seine Vertretung der „Riunione Adriatica di Sicurtà " und die von ihm angebotenen Leistungen an. Diese Annonce erschien in identischer Form auch in Nummer 32 vom 21. April und in Nummer 33 vom 24. April.

5.2. Es kommen bei J. Spierer zwar nicht alle Denotate vor, die in der Beschreibung der Dienstleistungen der „Azienda Assicuratrice“ aufscheinen, ein Vergleich ist aber trotzdem lohnend:

5.3. Für 'Schaden' verwendet Spierer nicht šteta, sondern ausschließlich kvar. Die Denotate für Versicherung (osiguranje) und 'Versicherungsgesellschaft' (družtvo za osiguranja) sind identisch mit denen in der Beschreibung der „Azienda Assicuratrice“, 'bewegliche Habe, Fahrnis' wird wie in der ersten Nummer des Jahrgangs 1847 von „Narodne novine“ als gibivo dobro bezeichnet. Die 'Feuerversicherung', die in „Narodne novine“ sonst osiguranje proti kvarom od požara genannt wird, wird bei Spierer genauso bezeichnet. Die 'Transportversicherung', die in der Beschreibung der ,Azienda Assicuratrice“ durch osiguravanje proti putnim pogibeljim pri prenosih od robe umschrieben wird, wird bei Spierer mit osiguranje proti svakoj pogibelji, kojoj su gibiva dobra na putu po vodi ili po kopnu izvèržena ausgedrückt. Die Wörter osiguranje und družtvo za osiguranja sind offenbar in der Sprache schon gefestigt, da sie in beiden - nur wenige Tage voneinander entfernten - Ankündigungen der Dienste einer Versicherung vorkommen, die 'Feuerversicherung' ist in ihrer Benennung in beiden Annoncen fast identisch, 'Transportversicherung' muss nach wie vor mit einer Umschreibung ausgedrückt werden, die nicht normiert ist und in der Beschreibung der „Riunione Adriatica di Sicurtà“ etwas anders ausfällt als in der „Azienda Assicuratrice“.

rechnen konnte, dass der im Ausbau befindliche Zivilisationswortschatz von den Lesern auch verstanden wurde."

13 Diese durch ein Synonym erklärten Wörter werden wir in einem weiteren Aufsatz behandeln - solche Wörter kommen nicht nur bei Lj. Gaj vor, sondern auch in anderen für dieses Forschungsprojekt exzerpierten Zeitschriften. - In einem Versicherungsverein auf Gegenseitigkeit zahlen alle Versicherten einen gewissen Betrag in einen Fonds ein, aus dem dann die Schadensfälle beglichen werden. Wenn dieser Fonds durch Entschädigungszahlungen nicht erschöpft wird, entsteht der Reservefond. Müssen hingegen mehr Entschädigungen ausgezahlt werden, als dafür von allen Vereinsmitgliedern Geld eingezahlt worden ist, entsteht die Notwendigkeit von Nachschüssen. (Vgl. Brockhaus 1986-1995 s. v. Versicherung.) 
6.1. Dieser Aufsatz zeigt anhand von Beispielen aus „Narodne novine“ und (aus pragmatischen Gründen) einem Beispiel aus „Danica ilirska““14, wie der Wortschatz betreffend das Versicherungswesen unter dem Einfluss der Illyrischen Bewegung gebildet wurde.

6.1.1. Einige Wörter blieben in ihrer Semantik erhalten, wurden aber in einem neuen Kontext - nämlich dem des Versicherungswesens - gebraucht (2.6.-2.7.).

6.1.2. Die bedeutungsmäßig wichtigsten Wörter dieses Wortschatzes - nämlich osigura(va)ti und osigura(va)nje - wurden einer Bedeutungsübertragung unterzogen, da sie in Abhängigkeit von ihrem Kontext die Sicherheit, die durch eine Versicherung gewährleistet wird, bezeichnen (2.1.-2.3.1.).

6.1.3. In einem Fall (2.3.2.) ist es zu einer Lehnprägung nach italienischem Vorbild gekommen.

6.1.4. Lehnübersetzungen erfolgten aus dem Deutschen (2.4.-2.5.).

6.1.5. Manche Denotate mussten ganz neu bezeichnet werden, was meist in einer mehr oder weniger ungeschlachten Umschreibung geschah (4.1.-4.3., auch 5.3.).

6.2.1. Von den bisher erwähnten Wörtern bzw. Wortbildungsarten sind diejenigen Wörter zu unterscheiden, die fremder Herkunft sind und daher den puristischen Tendenzen der Illyrischen Bewegung folgend mit kroatischen (oder wenigstens slawischen) Sprachmitteln gebildet werden mussten, z. B. agent $\rightarrow$ zastupnik oder agencia $\rightarrow$ opravničtvo (beide 3.1.).

6.2.2. Manche dieser mit kroatischen Mitteln gebildeten Wörter blieben nicht lange erhalten (3.2.-3.3., 4.1.-4.5.3.).

6.3. Da das ARj. „Narodne novine“ überhaupt nicht und „Danica ilirska“ nur zu einem geringen Teil in sein Material aufgenommen hat, können wir aus dem Material des beschriebenen Forschungsprojekts bis dahin unbekannte Erstbelege bieten, z. B. für Wörter, für die bis jetzt als Erstbeleg der Beleg aus der „Juridischpolitischen Terminologie für die slawischen Sprachen Oesterreichs (deutsch-kroat.serb.-sloven.)“, die in Wien 1853 erschienen ist, zitiert worden ist, z. B. osigurati, osiguranje, osiguratelj und šteta ${ }^{15}$.

7. Belege und Textbeispiele (in alphabetischer Ordnung der deutschen Bedeutung des behandelten Wortes):

7.1. 'auszahlen' izplatjivati (N28/1847, 114a/11): ... što zatim čistoga zaostane, onim će se izključivo izplatjivati štete, koje se ... dogode.

7.2. 'Auszahlung' izplatjivanje (N28/1847, 113/65-66): ..., ona bo suma odredjeno je izključivo samo za izplatjivanje štetah, ...

7.3. 'Agent (Versicherungsagent)' in 'Bezirksagent (einer Versicherung)' kotarski agenat (N28/1847, 114a/66): Preporučuje se ona (podpisana glavna agencia) i za Osiguravanja proti ... svim elementarnim kvarom, ...;- - o čem svakomu obilnu uba-

${ }_{15}$ Für dieses Beispiel bedanken wir uns bei der Mitarbeiterin Mag. Dr. Nevenka Petković.

15 Vgl. auch Mamić 1999: 71. 
věst daje kako podpisana glavna agencia, tako i slědeći gospoda kotarski agenti, kao: ...; heute zastupnik (Os. Z.); opravnik (N87/1847, 349/1/13): Smèrtju Matie Jurkovića izpražnjeno město kr<aljevskoga〉 ug〈arskoga〉 dvorskoga opravnika (agenta) poděljeno je Stěpanu Balassa; ...

7.4. 'Agentur' agencia (N28/1847, 113/58): Osiguravanja, ..., počinju od 1. Sěčnja ili 1. Sèrpnja ...; ona, koja kasnie stignu, počinju ... u jutru onoga dana, kojega je glavna agencia napisanu, ... prošnju za osiguranje primila i odobrila, ...; opravničtvo (N29/1847, 116/1/61): Doli podpisana uzima si čast te dostavlja do znanja štovanomu obćinstvu, da je za Zagreb i okolicu ... otvorila opravničtvo ... jadranskoga družtva za osiguranja (Riunione Adriatica di Sicurtà), ...

7.5. 'Bagatellschaden' šteta na jednom i istom predmetu, koje samo 5\% ili manje iznose (N28/1847, 113/50): ... i štete na jednom i istom predmetu, koje samo 5\% ili manje iznose, neće se naknadjivati.

7.6. 'bewegliches Gut, Fahrnis' gibivo dobro (N29/1847, 116/1/73): Uslěd ovoga obznanjenja preporučujem se štovanomu obćinstvu za prilično i bèrzo obskèrbljenje osiguranja ... 2) proti svakoj pogibelji, kojoj su gibiva dobra na putu po vodi ili po kopnu izvèržena.; gibivo imanje $(\mathrm{N} 28 / 1847,114 \mathrm{a} / 63)^{16}$ : Preporučuje se ona $\left[{ }^{17}\right.$ die unterschriebene Versicherungsagentur] i za Osiguravanja proti kvarom od požara na sgrade, gibiva imanja i spreme, ...

7.7. 'Entschädigung' naknada (N28/1847, 114a/13): ..., zato i oštetjeni nemogu očekivati i iskati veće naknade, ...

7.8. 'ermitteln' izviditi (N28/1847, 114a/6): Štete izvidit će se i procěniti polag pravilah, koja su štampana i za tu svèrhu knjižici od osiguranja priklopljena.

7.9. 'Feuerversicherung' osiguravanje proti kvarom od požara $(\mathrm{N} 28 / 1847,114 \mathrm{a} /$ 62): Preporučuje se ona (die unterzeichnete Versicherung) i za Osiguravanja proti kvarom od požara na sgrade, ...; bei Spierer osiguranje proti kvarom od požara (N29/1847, 116/1/69): Uslěd ovoga obznanjenja preporučujem se štovanomu obćinstvu za prilično i bèrzo obskèrbljenje osiguranja ... proti kvarom od požara, ...

7.10. 'Fonds' fond (N11/1847, 42/2/12): ... su se oni novci uzeli bili iz narodnoga fonda, za podpore oprědeljenoga; ...; fond (DI 14/1847, 56/2/17): Poznato će biti čitateljima iz novinah, kako je u banatskoj granici zaveden penzioni fond za iznemogle sèrbske učitelje, njihove udovice i siročad (vgl. Anm. 14); glavnica (N28/ 1847, 114a/20): ... izvišak iz jedne ili druge, ili iz obih periodah uzet će se, da se iz njega sklopi čuvarna glavnica (Reservefond). 7.11. 'Kapital' glavnica in 'Versicherungskapital' osiguravajuća glavnica (N28/1847, 114a/28): ... osiguravajuća glavnica oprostit će se od svakih dalnjih dužnostih.

${ }^{16}$ Die Angaben in Klammern sind wie folgt zu interpretieren: N28/1847 = Nummer 28 des Jahrgangs 1847 der Zeitung „Narodne novine“, 114a/63 = Seite 114a/(falls der Text in mehreren Kolumnen gedruckt ist, steht hier 1, 2 oder 3)/Zeile 63.

17 Textstellen in eckigen Klammern ergänzen die aus dem Zusammenhang gerissenen Sätze zum besseren Verständnis. 
7.12. 'Lebensversicherung' osiguranje života (N1/1847, 3/2/34-35): Robert Peel tim je pao, što parliament, imenito whigi, nisu hotěli primiti njegov predlog za osiguranje imanja i života u Irskoj.

7.13. 'Lebensversicherungsanstalt' družtvo za osiguranje života (N6/1847, 22/2/ 54-55): U Stolnom Biogradu osnovalo se je družtvo za osiguranje života (Lebensversicherungsanstalt), ...

7.14. 'Prämie (Versicherungsprämie)' premia (N28/1847, 113/63): Izvan premiah, koje će se polag izkustva svake godine ustanovljivati, mora osigurani ... još 15 krajcarah za namirivanje svih troškovah upravljanja platiti, ...

7.15. 'Reservefond' čuvarna glavnica (N28/1847, 114a/20): ... izvišak iz jedne ili druge, ili iz obih periodah uzet će se, da se iz njega sklopi čuvarna glavnica (Reservefond).

7.16. 'Schaden' in 'Schadenssumme' suma štetah (N28/1847, 114a/32): Stopram koncem Lipnja i Prosinca měseca dostavlja se ravniteljstvu do znanja ukupna suma štetah, ... und in 'Elementarschaden' elementarni kvar (N28/1847, 114a/64): Preporučuje se ona [podpisana glavna agencia] i za Osiguravanja proti svim elementarnim kvarom, ...; bei Spierer: Uslěd ovoga obznanjenja preporučujem se štovanomu obćinstvu za prilično i bèrzo obskèrbljenje osiguranje ... proti kvarom od požara, ... (N29/1847, 116/1/69)

7.17. 'schätzen' procěniti (N28/1847, 114a/6): Štete izvidit će se i procěniti polag pravilah, koja su štampana i za tu svèrhu knjižici od osiguranja priklopljena.

7.18. 'Statuten' štatute (N28/1847, 113/45): Ces〈arsko〉 kralj〈evska〉 Azienda Assicuratrice prima po smislu II. članka svojih družtvenih štatutah odsada osiguravanje i svih vodenih štetah, ...

7.19. 'Tarif' tarifa (N28/1847, 114a/3): ... tako isto je [svaki osigurani] u drugoj vlastitosti dužan odmah, kad svoju prošnju za osiguranje predade, u tarifi ustanovljene premie položiti, ...

7.20. 'Transport' prevoz (N7/1842, 25/2/4): ... morala bi naša tergovina (sic!) naskorom propasti, jerbo ... se i srědstva za oblakšanje prevoza (transporta) umnožavaju: ...

7.21. 'Transportversicherung' osiguravanje proti ... putnim pogibeljim pri prenosih od robe (N28/1847, 113/26): Azienda ... zadovoljila bude [pověrenje obćinstva] po drugom načelu, nego što proti štetam od požara i proti putnim pogibeljim pri prenosih od robe ... osiguravanja daje, ...; bei Spierer: osiguranje proti svakoj pogibelji, kojoj su gibiva dobra na putu po vodi ili po kopnu izvèržena (N29/1847, 116/1/68, 73-74): Uslěd ovoga obznanjenja preporučujem se štovanomu obćinstvu za prilično i bèrzo obskèrbljenje osiguranja ... 2) proti svakoj pogibelji, kojoj su gibiva dobra na putu po vodi ili po kopnu izvèržena.

7.22. 'unbewegliche Habe, Immobilie': negibivi imetak (N28/1847, 110/1/60): ..., koliko se je ... u ime troškovah prošastoga sabora na negibivi imetak povezalo; negibivo dobro (N28/1847, 113/47): Osigurat se mogu gibiva i negibiva dobra svake vèrsti, ... 
7.23. 'vergüten' namiriti (N28/1847, 114a/16): Ako bi ona [suma premiah] dovoljna bila za izplatiti sve, tad će se i sve štete podpuno namiriti; ... und namirivati (N28/1847, 114a/11): Iz sve ukupne sume, koja se u obih periodah jedne iste godine sabere, namirivat će se ponajprie troškovi, potrěbiti pri izvidjivanju i cěnjenju štetah; ...

7.24. 'Versicherer' osiguratelj (N28/1847, 113/41): ... azienda [die in diesem Aufsatz behandelte Versicherung in Triest] sačinila je slědeće uvěte osiguravanja, koji pravice i dužnosti osigurateljah i osiguranih sadèržavaju, ...

7.25. 'versichern' osiguravati (N28/1847, 113/27): ... ona [Assicuratrice Azienda] kao najstarii obćinski osiguravajući zavod u c. kr. austrianskih dèržavah obstoji. - Die Existenz von osigurati kann aus dem Vorhandensein der Wörter osiguratelj 'Versicherer' und osigurani 'Versicherter, Versicherungsnehmer' (N28/1847, 113/ 41) abgeleitet werden: ... azienda [die beschriebene Versicherung] sačinila je slědeće uvěte osiguravanja, koji pravice i dužnosti osigurateljah i osiguranih sadèržavaju, ... - älter 'sichern': osigurati (N7/1847, 27/1/36): Dugim izkustvom domašili smo politiku, koja ... ima osigurati u sadašnjosti njezino [domovine] blagostanje, ...; osiguravati (N22/1847, 86/1/21) Ovo obskèrbljenje sa svim, što trěba, osigurava neprekinuto obradjivanje rudnika bez pomoći gospode dionikah.

7.26. 'Versicherter, Versicherungsnehmer' osigurani (N28/1847, 113/42): ... azienda [die in diesem Aufsatz behandelte Versicherung in Triest] sačinila je slědeće uvěte osiguravanja, koji pravice i dužnosti osigurateljah i osiguranih sadèržavaju, ...

7.27. 'Versicherung' osiguranje (N1/1847, 4/2/24): Štedionica posudjuje uložene kod nje glavnice ... na ... robu, koja se lako nepokvari, pod nagradu magazine, osiguranjah i drugih troškovah.

7.28. 'Versicherung (Dienstleistung einer Versicherung)' osiguravanje (N28/ 1847, 113/5): Cesarsko-kr〈aljevska〉 povlastjena Azienda Assicuratrice u Tèrstu. Novi otvoreni odsěk. Osiguravanje proti vodenim štetam svake vèrsti; ...

7.29. 'Versicherung gegen Schäden durch Naturgewalten' osiguravanje proti svim elementarnim kvarom $(\mathrm{N} 28 / 1847,114 \mathrm{a} / 64)$ : ... podpisana glavna agencia ... preporučuje se ... za ... Osiguravanja proti svim elementarnim kvarom, kojim su gibiva dobra na putu po vodi ili kopnu izvèržena; ...

7.30. 'Versicherungsunternehmen': 'Versicherungsanstalt' osiguravajući zavod (N28/1847, 113/27): ... ona [die in diesem Aufsatz behandelte Versicherung in Triest] kao najstarii obćinski osiguravajući zavod u c<esarsko-> kr<aljevskih〉 austrianskih dèržavah obstoji. - 'Versicherungsgesellschaft' družtvo za osiguranja (N29/1847, 116/1/62): Doli podpisana uzima si čast te dostavlja do znanja štovanomu obćinstvu, da je za Zagreb i okolicu kod Gospodina Jakoba Spierera otvorila opravničtvo ... jadranskoga družtva za osiguranja (Riunione Adriatica di Sicurtà), ... - 'Versicherungsgesellschaft' osigurajuće družtvo (N26/1847, 101/2/67): Měseca ožujka lanjske godine ostalo je u družtvenoj pěneznici okolo 15,000 for<intih〉, ako $\mathrm{k}$ tomu dodame nagradu osigurajućeg družtva, ... 
7.31. 'Versicherer' osiguratelj (N28/1847, 113/41): ... azienda [assicuratrice u Trstu] sačinila je slědeće uvěte osiguravanja, koji pravice i dužnosti osigurateljah i osiguranih sadèržavaju, ...

7.32. 'Versicherter, Versicherungsnehmer' osigurani (N28/1847, 113/42): ... azienda [assicuratrice u Trstu] sačinila je slědeće uvěte osiguravanja, koji pravice $\mathrm{i}$ dužnosti osigurateljah i osiguranih sadèržavaju, ...; älter: udionik osiguranja (N28/ 1847, 113/31): ... se pako sve štete po svom podpunom iznosu razděljuju medju sve udionike osiguranja.

7.33. 'Versicherungsantrag' prošnja za osiguranje (N28/1847, 113/58-59): Osiguravanja, ..., koja kasnie stignu, počinju od 6te ure u jutru onoga dana, kojega je glavna agencia napisanu, kao sto trěba, prošnju za osiguranje primila i odobrila, ...

7.34. 'Versicherungsbedingung' uvět osiguravanja (N28/1847, 113/41): ... azienda [assicuratrice u Trstu] sačinila je slědeće uvěte osiguravanja, ...

7.35. 'Versicherungsbranche' struka osiguravanja $(\mathrm{N} 28 / 1847,114 \mathrm{a} / 61)$ : ... podpisana glavna agencia ... nada se mnogobrojnomu udioničtvu u ovoj novo-otvorenoj struci osiguravanja.

7.36. 'Versicherungskapital' osiguravajuća glavnica (N28/1847, 114a/28): ... osiguravajuća glavnica oprostit će se od svakih dalnjih dužnostih.

7.37. 'Versicherungssumme' osigurana suma (N28/1847, 114/9): Pri totalnom kvaru prestaje osiguranje, ali ne pri pomanjih kvarih, budući da ovo valja doklegod nenadilazi osiguranu suтu.

7.38. 'Versicherungswert' osigurana vrědnost (N28/1847, 113/64): Izvan premiah, ..., mora osigurani od svake stotine forintih osigurane vrědnosti još 15 krajcarah za namirivanje svih troškovah upravljanja platiti, ...

7.39. 'Wasserschaden' vodena šteta (N28/1847, 113/5): Cesarsko-kr<aljevska〉 povlastjena Azienda Assicuratrice u Tèrstu. Novi otvoreni odsěk. Osiguravanje proti vodenim štetam svake vèrsti; ...; šteta od vode (N28/1847, 113/13-14): ... da li se ljudi ne bi osiguravati mogli i proti štetam od vode; ...

7.40. 'Wasserversicherung' osiguravanje proti vodi (N28/1847, 113/17): ... nerazborito dělo od nas bilo, kad bi mi svoje glavnice takovom pogibelju oteretjavali, da ćemo osiguravanje proti vodi za ustanovljene darove davati,...

8. Der Ausbau des Wortschatzes betreffend das Versicherungswesen war 1847 keineswegs abgeschlossen. Wie aus dem ARj. ersichtlich ist, finden sich auch später noch Neuschöpfungen zu diesem Wortschatz in den Wörterbüchern von B. Šulek ${ }^{18}$, der einen großen Anteil an der Bildung des kroatischen Wortschatzes des 19. Jahrhunderts hatte.

\footnotetext{
${ }^{18}$ In der Folge wollen wir den Beitrag Šuleks zum kroatischen Wortschatz des 19. Jahrhunderts, soweit er aus dem Material des beschriebenen Forschungsprojekts ersichtlich ist, in einem eigenen Aufsatz darstellen.
} 


\section{Literatur}

Anić - Goldstein 2000: Vladimir Anić - Ivo Goldstein, Rječnik stranih riječi, Zagreb

ARj. 1884-1975: $\quad$ Rječnik hrvatskoga ili srpskoga jezika, Zagreb

Auty 1972:

Robert Auty, Sources and Methods of Lexical enrichment in the Slavonic Language - Revivals of the Early Nineteenth century, in: D. S. Worth, The Slavic Word: proceedings of the International Slavistic Colloquium at UCLA, The Hague, 41-52

Bauer 1942:

Ernst Bauer, Die Entwicklung der Publizistik in Kroatien, Zagreb

Behschnitt 1980:

Wolf Dietrich Behschnitt, Nationalismus bei Serben und Kroaten 1830-1914, Analyse und Typologie der nationalen Ideologie, München

Bußmann 2002: Hadumod Bußmann (Hrsg.), Lexikon der Sprachwissenschaft, Stuttgart

Despalatović 1975: Elinor Murray Despalatović, Ljudevit Gaj and the Illyrian Movement, East European Monographs 12, New York - London

Fancev 1936: $\quad$ Franjo Fancev, Ilirstvo u hrvatskom preporodu, Ljetopis JAZU 49, 130-157, in: Strossmayerov dan nauke i umjetnosti, posvećen proslavi 100-godišnjice hrvatskoga preporoda, 4. veljače 1936, 93-161

Garde 2004: $\quad$ Paul Garde, Le discours balkanique, Des mots et des hommes, Fayard

Hansen-Kokoruš 2005: Renate Hansen-Kokoruš, Josip Matešić, Zrinka Pečur-Medinger, Marija Znika: Deutsch-kroatisches Universalwörterbuch, Njemačko-hrvatski univerzalni rječnik, Red.: Josip Matešić und Dunja Brozović Rončević, Zagreb

Jonke 1958: $\quad$ Ljudevit Jonke, Osnovni problemi jezika hrvatske književnosti u 19. stoljeću, in: Sveučilište u Zagrebu, Filozofski fakultet, Radovi Slavenskog Instituta, osvećeni IV. međunarodnom sastanku slavista u Moskvi u mjesecu rujnu 1958., Zagreb, 75-91

Jonke 1965:

Ljudevit Jonke, Književni jezik u teoriji i praksi, Zagreb

Jonke 1975:

Ljudevit Jonke, Ljudevit Gaj kao višestruki pobjednik, Jezik 23, 6779

JPT 1853: Juridisch-politische Terminologie für die slawischen Sprachen Oesterreichs, Deutsch-kroatische, serbische und slovenische Separat-Ausgabe, Wien

Katičić 2004: $\quad$ Radoslav Katičić, Der auf Politisches bezogene Wortschatz der kroatischen Illyristen in den frühen vierziger Jahren des 19. Jahrhunderts, in: Gerhard Neweklowsky (Hrsg.), Herrschaft, Staat und Gesellschaft in Südosteuropa aus sprach- und kulturhistorischer Sicht, Erneuerung des Zivilisationswortschatzes im 19. Jahrhundert (= Österreichische Akademie der Wissenschaften, Schriften der Balkan-Kommission 48), Wien, 29-72

Katičić 2007: Radoslav Katičić, Ergebnisse des Symposiums und Schlusswort, in: Gerhard Neweklowsky (Hrsg.), Herrschaft, Staat und Gesellschaft in Südosteuropa aus sprach- und kulturhistorischer Sicht, Erneuerung des Zivilisationswortschatzes im 19. Jahrhundert (= Österreichische Akademie der Wissenschaften, Schriften der Balkan-Kommission 48), Wien, 303-308

Mamić 1999: $\quad$ Mile Mamić, Temelji hrvatskoga pravnog nazivlja, Zagreb (zweite, erweiterte Auflage)

Mažuranić - Užarević 1842: Ivan Mažuranić - Jakov Užarević, Deutsch-ilirisches Wörterbuch / Němačko-ilirski slovar, Zagreb

Metzler 1993

Metzler Lexikon Sprache, hrsg. v. Helmut Glück, Stuttgart - Weimar

Moguš 1995:

Milan Moguš, Povijest hrvatskoga književnoga jezika, Zagreb

Početci 2006:

Početci hrvatskoga novinstva i publicistike, Zagreb

Rammelmeyer 1975: Matthias Rammelmeyer, Die deutschen Lehnübersetzungen im Serbokroatischen, Beiträge zur Lexikologie und Wortbildung, Wiesbaden 
Skok 1971-1973: Petar Skok, Etimologijski rječnik hrvatskoga ili srpskoga jezika, Za-

Suppan 1996:

$\begin{array}{ll}\text { Suppan 1996: } & \text { Arnold Suppan, Der Ilyrismus Zwischen Wien und Ofen-Pest, Die il- } \\ & \text { lyrischen Zeitungen im Spannungsfeld der Zensurpolitik (1835 bis } \\ & \text { 1845), in: Andreas Moritsch (Hrsg.), Der Austroslavismus, Wien, } \\ & \text { 102-124 ̌ro } \\ & \text { Miroslav Sicel (Hrsg.), Riznica ilirska: 1835-1985, Zagreb - Ljublja- } \\ \text { Šicel 1985: } & \text { na } \\ & \text { Bogoslav Šulek, Nemačko-hrvatski rječnik, Zagreb } \\ \text { Šulek 1860: } & \text { George Thomas, The Impact of the Illyrian Movement on the Croatian } \\ \text { Thomas 1988: } & \text { Lexicon (= Slavistische Beiträge 223), München, } \\ & \text { Marija Turk, Jezični kalk: tipologija i nazivlje, Fluminensia 9, 1-2, } \\ \text { Turk 1997: } & \text { 85-104 }\end{array}$ greb

Abkürzungen

$\begin{array}{ll}\text { ARj.: } & \text { Rječnik hrvatskoga ili srpskoga jezika, Zagreb 1884-1975 } \\ \text { c. kr.: } & \text { cesaro-kraljevski } \\ \text { dalmat.: } & \text { dalmatinski } \\ \text { DI: } & \text { Danica ilirska } \\ \text { dtsch.: } & \text { deutsch } \\ \text { Hrsg.: } & \text { Herausgeber } \\ \text { hrsg.: } & \text { herausgegeben } \\ \text { kroat.: } & \text { kroatisch } \\ \text { l. c.: } & \text { loco citato } \\ \text { N: } & \text { Narodne novine } \\ \text { Nr.: } & \text { Nummer } \\ \text { Os. Z.: } & \text { Website der „Osiguranje Zagreb“ (Zugriff mehrmals, zuletzt am 01.12.08) } \\ \text { S.: } & \text { siehe } \\ \text { S.: } & \text { Seite } \\ \text { s. v.: } & \text { sub voce } \\ \text { serb.: } & \text { serbisch }\end{array}$

Kroatisches Wortregister

agen(a)t 2.6., 3.1., 6.2.1., 7.3.

agencia 3.1., 6.2.1.,7.4.

céniti 2.6.

čuvarna glavnica 3.2., 4.5.3., 7.15.

družtvo za osiguranje 2.4., 7.30.

družtvo za osiguranja 5.3., 7.30.

družtvo za osiguranje života 4.5.3., 7.13.

elementarni kvar 7.16.

fond 3.2., 7.10.

gibivo dobro 2.8., 5.3., 7.6.

gibivo imanje 2.8., 7.6.

glavnica 2.6., 3.2., 7.10., 7.11.

ilirski 1.1., 1.2.3.

izplatiti 2.6 .

izplatjivanje 2.6., 7.2.

izplatjivati 2.6., 7.1. 
izvidjeti 2.6., 7.8.

kotarski agenat 7.3.

kvar 2.6., 5.3., 7.16.

na(do)knada 2.6.

naknada 7.7 .

namiriti 7.23 .

namirivati 2.6., 7.23.

negibivi imetak 2.8., 7.22.

negibivo dobro 2.8., 7.22.

nekretnina 2.8 .

neznatna šteta 4.1 .

opravničtvo 3.1., 6.2.1., 7.4.

opravnik 3.1., 7.3.

osigurajuće družtvo 2.4., 7.30.

osigurajući zavod 2.4.

osigurana suma 2.5., 7.37.

osigurana vrědnost 2.5., 7.38.

osigurani 2.5., 7.25., 7.26., 7.32.

osiguranica 2.5 .

osiguranički 2.5 .

osiguranik 2.5 .

osiguranje 2.2.1., 2.2.2., 2.3.2., 5.3., 6.1.2., 6.3., 7.12., 7.27.

osiguranje od opasnosti požara 4.1 .

osiguranje proti kvarom od požara 4.1., 5.3.

osiguranje proti svakoj pogibelji, kojoj su gibiva dobra na putu po vodi ili po kopnu izvèržena 5.3., 7.21.

osiguranje proti vodi 4.3., 7.40.

osiguranje života $4.1 ., 7.12$.

osiguratelj 2.5., 6.3., 7.24., 7.25., 7.31.

osigurateljno društvo 2.4 .

osigurati 2.1., 2.3.2., 6.1.2., 6.3., 7.25.

osiguravajuća glavnica 2.5., 7.11., 7.36.

osiguravajuće društvo 2.4.

osiguravajući zavod 7.25., 7.30.

osiguravanje 2.3.1., 2.3.2., 6.1.2., 7.28.

osiguravanje proti kvarom od požara 4.1., 7.9.

osiguravanje proti (...) putnim pogibeljim pri prenosih od robe 4.2., 5.3., 7.21.

osiguravanje proti svim elementarnim kvarom 4.3., 7.29.

osiguravanje proti vodi 4.1., 7.40.

osigurati 6.1.2.

osiguravati 2.1., 2.3.2., 6.1.2., 7.25.

pokretnina 2.8 . 
premia 2.7., 7.14.

prenos 4.2 .

prevoz 3.3., 7.20.

prijevoz 3.3 .

procěniti 2.6., 7.17.

prošnja za osiguranje 2.5., 7.33.

sigur 2.3.2.

statute 2.6.

struka osiguravanja 2.5., 7.35.

suma šteta 7.16.

svota osiguranja 2.5 .

štatute 2.6., 7.18.

šteta 2.6., 5.3., 6.3, 7.16.

šteta na jednom i istom predmetu, koje samo 5\% ili manje iznose 4.1., 7.5.

steta od vode 4.3., 7.39.

tarifa 2.6., 7.19.

transport 3.3 .

transportno osiguranje 4.2 .

udionik osiguranja 2.5., 7.32.

uvět osiguravanja 2.5., 7.34.

vodena šteta 4.3., 7.39.

vrijednost osiguranog objekta 2.5 .

zastupnik 3.1., 6.2.1., 7.3.

životno osiguranje 4.1 .

A b stract: The formation of neologisms for the Croatian civilization vocabulary in the early 19th century: the example of the insurance industry vocabulary (1847). After 1835 the Illyrian Movement, the Croatian form of national awakening, strongly influenced Croatian cultural life, most notably the Croatian language: New words forming the vocabulary of civilization were to be composed of Croatian or at least Slavic elements. In 1847 insurances were offered in the newspaper as a new and practical thing. They had to be described by new terms - which were not always understood by all readers and had to be translated into German which was known to educated people then - or by old words with a new meaning. Some expressions were coined following the model of other - not necessarily Slavic languages. The Illyrian Movement had a strong impact on the Croatian language. This impact can be seen even today, even though not all of the newly coined words survived.

Keywords: Croatian language, beginning of the 19th century, national elements, vocabulary of civilization, new words

Eva Maria Ossadník

Österreichische Akademie der Wissenschaften

Balkan-Kommission,

Fleischmarkt 22, 1010 Wien, Österreich

eva-maria.ossadnik@oeaw.ac.at 